\title{
Outcome of surfactant therapy in a tertiary referral centre in Sri Lanka
}

\author{
K A N Menike ${ }^{1}$, M Weerasekera ${ }^{2}$ \\ Sri Lanka Journal of Child Health, 2009; 38: 25-27
}

(Key words: surfactant therapy outcome, Sri Lanka)

\begin{abstract}
Objective To assess the outcome of surfactant therapy at a tertiary referral centre in Sri Lanka

Design, setting and method All babies treated with surfactant at Sri Jayewardenepura General Hospital during 2007 were included in the study. Data on weight, maturity, age of ventilation, age of surfactant therapy, ventilator settings before and after surfactant, arterial blood gas results before and after surfactant, details regarding pneumothorax and pulmonary haemorrhage, duration of ventilation and chronic lung disease at 28 days, 3 months, and 6 months were collected. Data analysis was done according to maturity groups.
\end{abstract}

Results Forty eight babies had surfactant therapy during the study period. The commonest indication was hyaline membrane disease (HMD) in prematures (45), followed by meconium aspiration syndrome (03). According to maturity, $22(46 \%)$ were in 28 $33+$ weeks, followed by $12(25 \%)$ in $<28$ weeks, 11 $(23 \%)$ in $34-36+$ weeks and $3(6 \%)$ were $>37$ weeks (mature). Only $6(12 \%)$ babies in $34-36+$ weeks had transient hypoxia. None of them developed pneumothorax. Four (8\%) had features suggestive of pulmonary haemorrhage $12-48$ hours after surfactant replacement therapy. Four $(8 \%)$ babies had chronic lung disease at 28 days of age and two of them were in babies $<28$ weeks. The reduction in oxygen requirements was seen within 6 hours of therapy in $7 / 12,18 / 22,6 / 11$ in $<28,28-33+$ and $34-36+$ weeks babies respectively and in 12-24 hours in babies $>37$ weeks. There were 14 deaths comprising $5 / 12$ of babies $<28$ weeks, $5 / 22$ of $28-33+$ weeks, $4 / 11$ of 34$36+$ weeks. Duration of ventilation varied among the survivors; $5 / 7$ babies of $<28$ weeks needed $>10$ days of ventilation whereas $10 / 17$ of $28-33+$ weeks needed $<10$ days of ventilation.

\begin{tabular}{lrrr}
\hline${ }^{1}$ Senior Registrar & Neonatology, & ${ }^{2}$ Consultant \\
Neonatologist, $\quad$ Sri & Jayawardenepura & General \\
Hospital, Kotte, Sri Lanka &
\end{tabular}

(Received on 3 November 2008. Accepted on 24 November 2008)
Conclusions Reduction in oxygen requirement was seen within 6 hours of surfactant therapy in $65 \%$ of babies. Only $16 \%$ of babies who had surfactant therapy developed complications such as pulmonary haemorrhage and chronic lung disease. Duration of ventilation varied according to the maturity of the baby.

\section{Introduction}

Respiratory failure secondary to surfactant deficiency is a major cause of morbidity and mortality in preterm infants. Surfactant therapy substantially reduces mortality and respiratory morbidity for this population ${ }^{1}$. Secondary surfactant deficiency also contributes to acute respiratory morbidity in latepreterm and term neonates with meconium aspiration syndrome, pneumonia/sepsis, and perhaps pulmonary haemorrhage; surfactant replacement may be beneficial for these infants ${ }^{1}$. Single and multicentre randomized controlled trials have shown that the use of surfactant replacement in preventive or treatment modes has been safe and efficacious ${ }^{2,3,4}$. Overall benefits in the first 24 hours are improvement in oxygenation and a reduction in ventilatory pressure. The longer term effects are a reduction in pneumothoraces, periventricular haemorrhage, bronchopulmonary dysplasia and death ${ }^{5}$. So far no studies have been done in Sri Lanka regarding outcome of surfactant therapy.

\section{Objective}

To assess the outcome of surfactant therapy at a tertiary referral centre in Sri Lanka.

\section{Method}

All babies treated with surfactant at the Sri Jayewardenepura General Hospital during 2007 were included in the study. The first author collected all the data by a pretested questionnaire, and entered the details of the selected babies. These included: date of delivery, parity, maturity, birth weight, age at ventilation, clinical symptoms, ventilator settings and arterial blood gases before surfactant therapy, age of first dose of surfactant, details of any baby with 
features of pulmonary haemorrhage, details of babies with pneumothorax, ventilator settings and arterial blood gases after surfactant therapy according to time intervals ( $<6 \mathrm{hrs}, 6-12 \mathrm{hrs}, 12-24 \mathrm{hrs})$. This information was entered daily. The first author followed these babies at 28 days, 3 months and 6 months to see whether they were having any respiratory symptoms and signs. These details were obtained by directly examining babies and by using clinic records.

\section{Results}

Forty eight babies were given surfactant therapy during the study period. The commonest indication was HMD in prematures (45 babies). The other indication was meconium aspiration syndrome (3 babies). According to maturity, $12(25 \%)$ babies were $<28$ weeks of gestation, 22 (46\%) 28-33+ weeks, 11 (23\%) 34-36+ weeks, and $3(6 \%) 37$ weeks or greater.
Only $6(12 \%)$ babies in 34-36+ week group had transient desaturations. There were no cases of pneumothorax in the study group. Four $(8 \%)$ babies had features suggestive of pulmonary haemorrhage. One of them was from the $<28$ weeks group, one from the 28-33+ weeks and two from the 34-36+ week group. All of them developed signs within 12-48 hours of surfactant therapy.

Reduction in oxygen requirements was seen within 6 hours of surfactant therapy in $7 / 12,18 / 22,6 / 11$ in $<28,28-33+$ and $34-36+$ weeks babies respectively and within 12-24 hours in babies $>37$ weeks. Four babies $(8 \%)$ were on oxygen therapy even at 28 days of age. Two of them were from the $<28$ weeks group and one each from the 28-33+ weeks and 34-36+ week groups.

There were 14 deaths in the study group comprising $5 / 12$ of $<28$ weeks, $5 / 22$ of $28-33+$ weeks, $4 / 11$ of 34-36+ weeks. The deaths are analysed in table 1 .

Table 1

Analysis of deaths

\begin{tabular}{|l|c|c|c|}
\hline \multicolumn{1}{|c|}{ Cause of deaths } & $<\mathbf{2 8}$ weeks & $\mathbf{2 8 - 3 3 +}$ weeks & $\mathbf{3 4 - 3 6 +}$ weeks \\
\hline IRDS & 1 & 1 & 2 \\
\hline Pulmonary haemorrhage & 1 & 1 & \\
\hline Chronic lung disease & 1 & 1 & \\
\hline Septicaemia & 2 & 1 & \\
\hline Intraventricular hemorrhage & & 1 & 1 \\
\hline Renal failure & & & \\
\hline Congenital heart disease & & & \\
\hline
\end{tabular}

Duration of ventilation varied. Five of 7 babies from the $<28$ weeks group needed more than 10 days of ventilation whereas 10 of 17 babies from the 28-33+ weeks group, 4 of 7 babies from the 34-36+ week group and 2 of 3 babies from the $>37$ weeks group needed less than 10 days of ventilation.

\section{Discussion}

Surfactant replacement therapy for babies with HMD is one of the life saving therapeutic advances in neonatology. Surfactant can be given as prophylactic or as rescue therapy. As a unit in a developing country with significant financial constrains, at Sri Jayewardenepura General Hospital it is generally given as rescue therapy. We usually give one dose $(4 \mathrm{ml} / \mathrm{kg})$ for those needing respiratory support. We use a second dose if oxygen requirement is $>25 \%$ 8 - 12 hours after the first dose.

Although surfactant replacement therapy is expensive, it has beneficial effects especially when managing premature babies. It is clear that oxygen requirement was reduced within 6 hours of therapy in the majority of babies thus reducing oxygen related complications in premature babies. The strongest grounds for continuing surfactant therapy is that only $16 \%$ developed complications such as pulmonary haemorrhage and chronic lung disease. There were no cases of pneumothorax.

\section{Conclusions}

- Reduction in oxygen requirement was seen within 6 hours of surfactant therapy in $65 \%$ babies.

- Only $16 \%$ babies who had surfactant therapy developed complications such as pulmonary haemorrhage and chronic lung disease.

- Duration of ventilation varied according to the maturity of the baby. 


\section{Acknowledgements}

We thank the staff of the NICU SJGH for their help and the mothers of those babies who gave consent to take part in the study.

\section{References}

1. Engle WA and the Committee on Fetus and Newborn. Surfactant-replacement therapy for respiratory distress in the preterm and term neonate. Pediatrics 2008; 121 (2): 41932 .

2. Corbet A, Bucciarelli R, Goldman S, Decreased mortality rate among small premature infants treated at birth with a single dose of synthetic surfactant: a multicenter controlled trial. Journal of Paediatrics 1991; 118:277-84.
3. Kendig JW, Notter RH, Cox C, A comparison of surfactant as immediate prophylaxis and as rescue therapy in newborns of less than 30 weeks' gestation. New England Journal of Medicine 1991; 324:865-71.

4. Schwartz RM, Luby AM, Scanlon JW, Kellogg RJ. Effect of surfactant on morbidity, mortality, and resource use in newborn infants weighing 500 to $1500 \mathrm{~g}$. New England Journal of Medicine 1994; 330:1476-80.

5. Morley CJ. Surfactant therapy for very premature babies. British Medical Bulletin 1988; 44: 919-34. 